\title{
ENTREVISTA COM O SOCIOLINGUISTA FRANCISCO MORENO FERNÁNDEZ
}

\author{
ENTREVISTA AL SOCIOLINGÜISTA FRANCISCO MORENO FERNÁNDEZ
}

INTERVIEW WITH SOCIOLINGUIST FRANCISCO MORENO FERNÁNDEZ

\author{
Egisvanda Isys de Almeida SANDES ${ }^{1}$ \\ Antonio MANJÓN-CABEZA CRUZ ${ }^{2}$ \\ Elena Fernández de MOLINA ORTÉS ${ }^{3}$
}

RESUMO: Trata-se da entrevista que Sandes, Manjón-Cabeza Cruz e Molina Ortés fazem com um dos ícones da sociolinguística hispânica, Francisco Moreno Fernández. Desde 1995, o entrevistado é diretor do projeto internacional PRESEEA (Projeto para o Estudo Sociolinguístico do Espanhol da Espanha e da América) e possui mais de 200 publicações entre livros, capítulos, artigos e resenhas. Embora grande parte de sua pesquisa esteja relacionada com a dialetologia e a sociolinguística hispânicas, Moreno Fernández também trabalha nos âmbitos da semântica e da lexicografia e, ainda, na área de ensino de línguas. $\mathrm{Na}$ entrevista, o premiado sociolinguista trata de diversos aspectos como seu início como pesquisador, sua linha de pesquisa, questões relativas à área no contexto espanhol e fora do país, controvérsias e coincidências nas discussões entre autores, bem como sobre a importância da sociolinguística para o ensino de línguas.

PALAVRAS-CHAVE: Francisco Moreno Fernández. Entrevista. Sociolinguística e ensino de línguas.

RESUMEN: Se trata de la entrevista de Sandes, Manjón-Cabeza Cruz y Molina Ortés a uno de los íconos de la sociolingüística hispánica, Francisco Moreno Fernández. Desde 1995, el entrevistado ha sido director del proyecto internacional PRESEEA (Proyecto para el Estudio Sociolingüístico del Español en España y América) y tiene más de 200 publicaciones que incluyen libros, capítulos, artículos y reseñas. Aunque gran parte de su investigación está relacionada con la dialectología y la sociolingüística hispana, Moreno Fernández también trabaja en los campos de la semántica y la lexicografía y, además, en el área de enseñanza de lenguas. En la entrevista el galardonado sociolingüista aborda varios aspectos, como su inicio como investigador, su línea de investigación, cuestiones relacionadas con el área en el contexto español y en el extranjero, controversias y coincidencias entre las discusiones de los autores, así como sobre la importancia del sociolingüistica para la enseñanza de lenguas.

\footnotetext{
${ }^{1}$ Universidade Estadual Paulista (UNESP), Araraquara - SP - Brasil. Docente do Departamento de Letras. Pósdoutora pela Universidade de Granada (UGR) e Universidade de Educação a Distancia (UNED). ORCID: http://orcid.org/0000-0003-3824-146X. E-mail: egisvanda.sandes@unesp.br

${ }^{2}$ Universidad de Granada, Granada - Espanha. Professor Titular do Departamento de Língua Espanhola, Facultad de Filosofía y Letras. ORCID: http://orcid.org/0000-0002-2112-3793. E-mail: amanjoncabeza@ugr.es

${ }^{3}$ Universidad de Granada, Granada - Espanha. Professora Doutora do Departamento de Língua Espanhola da Facultad de Filosofía y Letras. ORCID: https://orcid.org/0000-0002-9907-7985. E-mail: efortes@ugr.es
} 
PALABRAS CLAVE: Francisco Moreno Fernández. Entrevista. Sociolingüística y ensenãnza de lenguas.

ABSTRACT: This is the interview that Sandes, Manjón-Cabeza Cruz and Molina Ortés do with one of the icons of Hispanic sociolinguistics, Francisco Moreno Fernández. Since 1995, the interviewee has been director of the international project PRESEEA (Project for the Sociolinguistic Study of Spanish in Spain and America) and has more than 200 publications among books, chapters, articles and reviews. Although much of his research is related to dialectology and Hispanic sociolinguistics, Moreno Fernández also works in the fields of semantics and lexicography and also in the area of language teaching. In the interview, the award-winning sociolinguist deals with several aspects such as his beginning as a researcher, his investigative line, issues related to area in the Spanish context and abroad, controversies and coincidences in the discussions between authors, as well as on the importance of sociolinguistics for the teaching of languages.

KEYWORDS: Francisco Moreno Fernández. Interview. Sociolinguistics and language teaching.

\section{Introdução}

Francisco Moreno Fernández ${ }^{4}$ nasceu em Mota del Cuervo (Cuenca), Espanha. É doutor em Linguística Hispânica pela Universidade Complutense de Madrid (1984) e bacharel em Ciências Políticas e Sociologia pela UNED (2010). Renomado dialetólogo e sociolinguista espanhol, é catedrático de Língua Espanhola na Universidade de Alcalá (Espanha) e catedrático premiado pela fundação Alexander von Humboldt na Universidade de Heidelberg (Alemanha), onde reside atualmente. Além de ter sido galardoado com diversos prêmios por conta de seu trabalho científico, é acadêmico correspondente da Academia Cubana de Língua Espanhola (2012), da Real Academia Espanhola por Castilla-La Mancha (2016), da Real Academia Espanhola pela América Latina (2017), da Academia Chilena da Língua (2017), da Academia Mexicana da Língua (2018), Acadêmico de número da Academia Norte-americana de Língua Espanhola (2017) e doutor honoris causa pela Universidade Ricardo Palma (Peru) (2017).

Como professor em instituições espanholas e ao redor do mundo (Brasil, EUA, Suécia, Chile, entre outros) e como diretor acadêmico do Instituto Cervantes de diversos lugares

${ }^{4}$ Página da Web: http://www.linguas.net

Currículo:https://www.linguas.net/Espaciospersonales/EspacioFranciscoMorenoFern\%C3\%A1ndez/Curr\%C3\% ADculum/tabid/76/language/es-ES/Default.aspx /

E-mails: francisco.moreno@uah.es; francisco.moreno@uni-heidelberg.de 
(Espanha, São Paulo, EUA, entre outros) e da Fundação Comillas (2006-2008) registra suas pesquisas em importantes materiais sobre a língua espanhola, no que tange ao ensino da sociolinguística como um todo. A respeito de sua pesquisa em linguística geral e aplicada da língua espanhola é importante ressaltar a direção do projeto internacional PRESEEA (Projeto para o Estudo Sociolinguístico do Espanhol da Espanha e da América) desde 1995, a coordenação do Atlas Linguístico (e etnográfico) de Castilla-La Mancha (1988-2003) e a direção do projeto Integração sociolinguística da população imigrante na Espanha (20062009), entre outros direcionados à dialetologia e à sociolinguística do espanhol.

Conta com mais de 200 publicações (livros, capítulos, artigos, resenhas). Grande parte se relaciona com os campos da dialetologia e da sociolinguística hispânicas, como as conhecidas obras Principios de Sociolingüística y Sociología del Lenguaje (1998; 4ª ed. 2009), Las variedades de la lengua española y su enseñanza (2010) e Sociolingüística cognitiva (2012), e as recentes, La maravillosa historia de la lengua española (2015), A Framework for Cognitive Sociolinguistics (2016), Tras Babel. De la naturaleza social del lenguaje (2018). Além disso, também trabalhou no âmbito da semântica e da lexicografia com a publicação de dicionários, e, no campo do ensino de línguas, dirigiu projetos educacionais, de formação de professores e produção de materiais didáticos, publicou livros como Qué español enseñar (2000), Adquisición de segundas lenguas: variación y contexto social (ed. 2000), Producción, expresión e interacción oral (2001), Las variedades de la lengua española y su enseñanza (2010) e escreveu inúmeros artículos e os capítulos «Spanish»e «Instituto Cervantes» da Routledge Encyclopedia of Language Teaching and Learning.

Por sua vasta e significativa produção, além de sua participação em mais de 70 congressos nacionais e internacionais, com palestras, comunicações, mesas redondas e painéis, Moreno Fernández é conhecido como um dos grandes sociolinguistas da língua espanhola em todo o mundo.

Professor, agradecemos muito por sua participação nesta entrevista e gostaríamos de conhecer um pouco mais sobre seu trabalho no tema desenvolvido neste número.

\section{Entrevista}

\section{Em que momento de seus estudos você teve contato com a sociolinguística?}


Meu primeiro contato com a disciplina sociolinguística se deu durante meus estudos universitários. Portanto, falo do início dos anos oitenta, a sociolinguística não existia como matéria nos planos de estudo da Filologia na Espanha. Como se sabe, havia disciplinas de História da Língua Espanhola e da Dialetologia Espanhola, mas não uma Sociolinguística propriamente dita. Pensemos que os primeiros trabalhos influentes de William Labov, mentor deste campo em sua formulação moderna, foram sendo divulgados fora dos Estados Unidos ao longo da década de sessenta.

\section{Que profesor(es) o orientaram a ela?}

O professor que mais influenciou na minha inclinação para a sociolinguística foi, sem dúvidas, Manuel Alvar, com quem cursei as matérias de Dialetologia hispânica e Geografia linguística na Universidade Complutense. Depois, por intermédio de Alvar, tive a sorte de conhecer Humberto López Morales, quem me incentivou definitivamente a seguir o caminho da sociolinguística, como também me incentivou Ángel López García. Em meados dos anos oitenta, ganhei uma bolsa da Fulbright que me levou aos Estados Unidos, mais especificamente a Albany, na Universidade do Estado de Nova Yorl, onde Arnulfo Ramírez e Francine Frank eram professores. Ambos me abriram outros horizontes da sociolinguística, como o de sua aplicação no ensino, no caso de Ramírez, ou o dos estudos feministas, no caso de Frank.

3. Quais foram as leituras que fundamentaram sua trajetória? Como você tem desenvolvido sua pesquisa em sociolinguística e que evolução teve sua trajetória investigativa neste âmbito?

Manuel Alvar publicou, no início dos anos setenta, o livro Niveles socioculturales en el habla de Las Palmas de Gran Canaria, onde se vertiam os princípios de uma dialetologia social e de uma sociolinguística que estava dando seus primeiros passos. Esta foi uma leitura fundamental para meus novos interesses. Também nos anos setenta o Projeto para o Estudo da Norma Culta das principais cidades do mundo hispânico (PILEI) foi tomando forma. Mas, definitivamente, a leitura que mais me influenciou, a partir de uma perspectiva metodológica, foi Estratificação social do espanhol de San Juan de Puerto Rico, de Humberto López Morales. Lembro que, em dezembro de 1983, no simpósio da Sociedade Espanhola de Linguística, Humberto López Morales se aproximou e me disse: "Este meu livro acabou de sair no México. Tenho apenas três exemplares e quero que um seja para você”. O entusiasmo 
que pude sentir neste momento é facilmente imaginável. Depois chegaram as leituras do primeiro Labov e dos pesquisadores da escola do Canadá: Cedergren, Poplack, Sankoff... Estes trabalhos foram muito atraentes para mim por conta do método, ainda que, naquele momento, me escapavam muitos detalhes da análise sociolinguística do inglês, que tive que ir aprendendo aos poucos. Acostumado a estudar uma língua como o espanhol, com suas importantes variações consonantais, aquela coisa do "grande deslocamento vocálico" ou das elisões das cópulas, me pareciam distantes. Talvez por isso me direcionei a fazer uma sociolinguística acessível para os estudantes de origem hispano.

\section{De suas primeiras pesquisas, do que você lembra com especial carinho ou aversão?}

Na verdade, nenhuma pesquisa me provocou aversão, nem entre as primeiras, nem entre as últimas. Toda pesquisa é um estímulo e uma oportunidade de aprender. Para um pesquisador, poucas coisas são tão emocionantes quanto levantar perguntas de pesquisa e refletir sobre a forma de abordá-las, para depois atentar-se a elas. Guardo uma lembrança especial de meus trabalhos de campo para realizar a tese de doutorado: a abordagem da hipótese, a elaboração do questionário, sua fabricação artesanal, a busca por entrevistados, o contato com as pessoas... Além disso, quis realizar a análise com o auxílio da informática da época. Para isso, tive que recorrer ao Centro de Cálculo de la Complutense e, finalmente, ao da Universidade de Tokio, onde meu amigo Hiroto Ueda procedeu de maneira conjunta todos os meus materiais coletados. Esta primeira experiência como o mundo dos computadores me impactou muito. Depois fui me dando conta do que supunha na primeira metade dos anos oitenta: combinar critérios sociolinguísticos e pragmáticos a propósito de atos de fala coloquiais (cumprimentos, despedidas, convites...). Naquela época não havia antecedentes na Espanha que tratassem destes aspectos de uma perspectiva quantitativa. Tanto é que um membro da banca que julgou minha tese chegou a me dizer que aquilo não era Linguística. Naquele momento, este julgamento me afetou muito porque um estudioso novato sempre aspira se destacar a partir de uma suposta ortodoxia, ainda que, com o tempo, você se da conta de que a ortodoxia não é tão importante quanto a originalidade, quanto a inovação ou a curiosidade. Depois da tese de doutorado, meu primeiro grande projeto foi o Atlas Linguístico (e etnográfico) de Castilla-La Mancha, que realizei com Pilar GarcíaMouton e que abria um espaço notável à dimensão linguística; tanto que, ainda hoje, temos explorado os materiais reunidos em todas suas possibilidades. A experiência humana de 
realizar uma pesquisa de campo de muitos anos, com centenas de entrevistados, leva a uma aprendizagem incomparável.

\section{Onde pode se situar a sociolinguística hispânica / na Espanha? Tendências... grupos...}

A sociolinguística hispânica foi crescendo no ritmo da sociolinguística geral, em interesses, tendências, métodos... Trata-se de uma disciplina que tem se calcado com força na Europa, onde ocupa um respeitável espaço; certamente muito mais do que ocupa nos Estados Unidos, quase monopolizados por uma linguística formal de recorte gerativista que olha com desdém os pesquisadores de viés social. Também ganhou força na Ibero-América, pela influência recebida a partir da sociolinguística estadunidense e espanhola. Na Espanha, há décadas, existem muitas tendências de estudo sociolinguístico: umas inclinadas a questões de bilinguismo e ideologia, outras interessadas pela interseção entre o geográfico e o social; outras centradas no estudo da variação e mudança. Uma parte da abordagem pessoal se relaciona, precisamente, com a criação de uma grande rede de pesquisa, chamada PRESEEA, realizada com Carmen Silva-Corvalán e Humberto López Morales (Projeto para o Estudo Sociolinguístico do Espanhol da Espanha e da América), integrada por equipes de mais de 40 comunidades em que participaram centenas de pesquisadores e que já produziu uma grande quantidade de estudos e livros, assim como numerosas dissertações de mestrado e teses de doutorado.

\section{Há revistas de Sociolinguísticas na Espanha ou na Hispano-América?}

Nos países falantes de espanhol, há revistas, algumas importantes, que publicam trabalhos de sociolinguística: Nueva Revista de Filología Hispánica, Lingüística Española Actual, Revista Signos, Lengua y Migración... Não são revistas exclusivamente de sociolinguística, porém abrem espaço para esta disciplina. O mesmo ocorre com outras revistas, como a Revista Internacional de Lingüística Iberoamericana. Nestes momentos, a publicação mais preocupada por aspectos sociolinguísticos do espanhol, ainda que não somente, é a revista bilíngue Spanish in Context, cuja sede se encontra na Holanda, mas nós, editores, estamos divididos entre os Estados Unidos, Espanha e Reino Unido. Em todo caso, o panorama editorial tem mudado muito nos últimos anos. Agora, a sociolinguística do espanhol se realiza também a partir de revistas internacionais, em sua maioria de origem 
britânica ou estadunidense, mas de dinâmica multinacional, nas quais publicam especialistas falantes de espanhol de qualquer país, em inglês.

7. Você acredita que a sociolinguística está sendo suficientemente representada nos planos de estudo de sua Universidade? Como? Em que níveis? Graduação ou Mestrado? Como tem evoluído esta presença?

Atualmente, estou trabalhando principalmente na Universidade de Heidelberg, na Alemanha, onde dirijo um recém-nascido Centro de Estudos Ibero-americanos. No plano de estudos de Filologia Românica de Heidelberg a presença da Sociolinguística como matéria é mínima, para não dizer inexistente. Espero que minha presença nesta universidade tenha algum efeito a este respeito. Quanto à Universidade de Alcalá, na Espanha, com a que sigo mantendo um estreito vínculo formal e afetivo, a Sociolinguística tem uma presença já consolidada, tanto na linha dos estudos de variação, quanto em uma linha de sociologia da língua. Os planos de estudo de Graduação em Estudos Hispânicos incluem matérias de conteúdo sociolinguístico, assim como os estudos de Pós-graduação. Do mesmo modo, as teses e dissertações elaboradas sobre esta matéria foram e ainda são numerosas, ultimamente muito interessadas em questões de integração sociolinguística de população migrante, bem como de aplicação ao ensino de línguas.

8. Uma pregunta para a controvérsia: existem suas posturas entre os sociolinguistas hispânicos (e não hispânicos) porque uns pensam que a sociolinguística supõe uma ruptura epistemológica com a linguística anterior, enquanto outros pensam que é uma consequência da dialetologia, o que você pensa sobre isso?

A sociolinguística sempre mostrou uma face continuísta e uma face inovadora. Recordemos que a primeira sociolinguística de Labov tentou oferecer uma alternativa ao conceito de "regra" do gerativismo, mas com o fim de melhorar o modelo, não de substituilo. As coisas, finalmente, têm levado a um progressivo distanciamento de ambas escolas. No entanto, como sociolinguista, devo ficar com uma das primeiras manifestações de William Labov: toda linguística é social por definição; ou seja, toda linguística há de ser sociolinguística. É evidente que a linguagem tem uma dimensão biológica e neurológica, mas sua compreensão é incompleta sem a dimensão social. Inclusive o cognitivismo se revelou compatível com as abordagens sociológicas. Quanto à dialetologia, trata-se de um claro antecedente com o qual a sociolinguística tem contribuído e enriquecido, até o ponto que tal enriquecimento chegou a ser entendido como um processo de substituição epistemológica. No 
entanto, a dimensão geográfica da língua, a de maior interesse para a dialetologia, não perdeu sua identidade e hoje está se manifestando em estudos dialetais abordados a partir de diferentes perspectivas, teóricas e metodológicas. Hoje se segue fazendo dialetologia, mas não com os métodos de comparatismo, de historicismo ou de estruturalismo, mas com os próprios das tendências atuais. Tudo isso é um reflexo para além da "linguística”, em geral, de um conhecimento acumulativo progressivo. Existe uma dinâmica de paradigmas de pesquisa que vão sendo sobrepostas e sucedidas progressivamente. Nesta sucessão de paradigmas, a sociolinguística tem ampliado os limites de sua esfera de interesses e buscado mais e maiores inter-relações com outros âmbitos do saber.

9. Outra questão para a controvérsia: há estudiosos que pensam que a chamada terceira onda (atenção ao falante específico) pode significar retornar a paradigmas de estudos próximos à dialetologia. Qual sua opinião sobre isso?

Efetivamente, a terceira onda proposta por Penelope Eckert se interessa mais pelo espaço estilístico e pela figura de um falante entendido como um ator social capaz de ocupar diferentes posições discursivas dentro de alguns espaços sociais e culturais concretos. A figura do "falante" na sociolinguística atual não tem nada a ver com a figura do falante na dialetologia tradicional, especialmente na geografia linguística. Atualmente, é utilizado um conceito muito mais rico e complexo. No entanto, se os trabalhos dialetológicos seguem tendo seu significado é porque os falantes, como indivíduos, também reúnem suas condições de valor. Contudo, o tratamento analítico dado à figura do falante mudou de modo radical.

\section{Considera que há âmbitos do estudo da variação que ainda não foram desenvolvidos ou recebido pouca atenção?}

A realidade dialetal e a sociolinguística são mutáveis porque são sensíveis às transformações sociais. Isso faz que com os estudos da variação não possam nunca se dar por conclusos. Pessoalmente, estou inclinado a pensar que o campo da comunicação em pequenos e médios grupos ainda contém muitos aspectos a serem descobertos, que também afetam a variação, mas não apenas. A interseção da psicologia, da psicologia social, da sociologia e da linguística deverão ser um espaço muito frutífero. Refiro-me, por um lado, ao conhecimento do que se denomina o "cérebro social”, em todas as manifestações linguísticas e, por outro, ao conhecimento sobre a dinâmica das redes e dos sistemas complexos. 
11. O que você acha das técnicas e métodos usados na sociolinguística? Após quase 60 anos dos primeiros estudos, eles devem ser modificados, expandidos ou retocados?

O fato de lidar com dados reais, geralmente em importantes quantidades, faz com que estas disciplinas estejam sempre em condições de aproveitar os avanços que a informática e a estatística oferecem, bem como as técnicas de transmissão, armazenamento e recuperação de grandes quantidades de informação. Em minha opinião, o desenvolvimento da inteligência artificial abrirá todo um universo de possibilidades ao estudo da variação e mudança linguística.

\section{Poderia resumir alguma de suas pesquisas/publicações mais recentes? A que está se dedicando agora?}

Atualmente, a maior parte do meu tempo dedico aos trabalhos de criação do Centro de Estudos Ibero-americanos, compromisso assumido com a Fundação Humboldt e com a Universidade de Heidelberg quando me concederam o prêmio internacional Alexander von Humboldt 2020. Porém, é claro que não abandono a pesquisa. Estou muito interessado pelas implicações sociolinguísticas do conceito de identidade, bem como pelas consequências linguísticas da globalização. Em alguns meses publicarei um ensaio em que reflito sobre tudo isso. Também me interessa a dimensão sociolinguística do envelhecimento e, ao mesmo tempo, tento avançar e melhorar os métodos da demolinguística, que em outros momentos realizei a partir de uma perspectiva mundial (macro) e que agora quero desenvolver a partir de uma perspectiva micro. Provavelmente desenvolverei com a equipe de Heidelberg a respeito do espanhol na Europa e, mais especificamente, na Alemanha.

\section{Você acredita que formou escola: teses, seguidores, artigos compartilhados, etc.?}

Nada me desagradaria mais que criar uma escola, já que, em poucos anos, as escolas ficam relegadas a uma pequena quantidade de linhas da historiografia linguística ou, no máximo, a uma página da Wikipedia. O que é hoje o círculo de Praga na linguística ou a escola de Fankfurt na filosofia? São histórias. Chame-se Escola ou não, não gosto que se saiba que na Universidade de Alcalá se aprende a fazer boa sociolinguística, quaisquer que sejam as abordagens teóricas que tocam em qualquer momento. Naturalmente, gosto de compartilhar autoria com colegas e amigos, o que tenho feito desde a minha primeira publicação sobre os nomes de um pássaro chamado conjugada, até os últimos artigos 
escritos com Hiroto Ueda ou Domnita Dumitrescu. Tenho que confessar, não obstante, que o que mais me causa satisfação é receber mensagens de muitos lugares do mundo, sobretudo da América, de estudantes que dizem que meus trabalhos lhes foram úteis, por qualquer que seja o motivo. Sei que alguns livros meus circulam em PDF e são distribuídos em forma de rede livre de escola. Sei também que isso não é bom para os direitos do autor, mas, como poucos ficam ricos com a linguística, prefiro ficar com a satisfação de poder ter sido útil aos estudantes.

14. Por último, este volume é dedicado à sociolinguística e ao ensino, que tipo de relação se estabelece entre elas, em sua opinião?

Evidentemente, uma relação muito estreita: se o ensino é um pouco contextualizado e sensível aos fatores sociais, como de fato é, a sociolinguística tem muito que dizer a respeito. Com efeito, algumas teorias da aquisição têm um importante fundamento social, como se aprecia nos trabalhos de Vygotsky ou, em outra linha, nos de Schumann. Há alguns anos escrevi um artigo sobre as abordagens da sociolinguística e do ensino de línguas que ainda segue circulando profusamente, a pesar de que já requer uma atualização.

\section{Gostaria de acrescentar alguma consideração ou algum comentário acerca do tema da entrevista ou da sociolinguística em geral?}

Gostaria apenas de incentivar os pesquisadores mais jovens, meninas e meninos que se interessam pelo uso real da linguagem, a adotarem a sociolinguística. Nela encontrarão uma perspectiva gratificante, por sua proximidade a questões que interessam às pessoas $e$ por sua permanente renovação, conforme as sociedades evoluem e nossos conhecimentos sobre a(s) língua(s) avançam.

\section{Como referenciar esta entrevista}

SANDES, Egisvanda Isys de Almeida; MANJÓN-CABEZA CRUZ, Antonio;MOLINA ORTÉS, Elena Fernández de. Entrevista com o sociolinguista francisco Moreno Fernández. Rev. EntreLínguas, Araraquara, v. 6, n. 1, p. 11-21, jan./jun., 2020. e-ISSN: 2447-3529. DOI: https://doi.org/10.29051/el.v6i1.13727

Submetido em: 30/07/2019

Revisões requeridas: 30/08/2019 
Aceito em: 30/11/2019

Publicado em: 06/01/2020 